\title{
Stage IIIB Cervical Cancer AJCC v6 and v7
}

National Cancer Institute

\section{Source}

National Cancer Institute. Stage IIIB Cervical Cancer A/CC v6 and v7. NCI Thesaurus.

Code C6321.

Stage IIIB includes: (T3b, Any N, M0); (T1-3, N1, M0). T3: Tumor extends to pelvic wall and/or involves lower third of vagina, and/or causes hydronephrosis or non-functioning kidney. T3b: Tumor extends to pelvic wall and/or causes hydronephrosis or nonfunctioning kidney. N1: Regional lymph node metastasis. M0: No distant metastasis. (AJCC 6th and 7th eds.) 